\title{
МЕТОД РАСЧЕТА ТЕПЛОВЛАЖНОСТНЫХ ПАРАМЕТРОВ РУДНИЧНОГО ВОЗДУХА
}

\section{Ш. И. Ониани}

Руководитель лаборатории горной теплофизики; Институт горной механики имени Г. А. Цулукидзе Академия Наук Грузинской ССР, Тбилиси, СССР

О. А. Ланчава, С. Л. Болквадзе

Научные сотрудники той же лаборатории

В связи с освоением глубоких горизонтов шахт и рудников возникла проблема прогноза и регулирования тепловлажностных параметров вентиляционной струи, которая остается актуальной по сей день. Для оптимального решения вопросов тепловлажностного кондиционирования рудничного воздуха необходимо дальнейшее развитие и уточнение методов прогнозирования климатических условий глубоких шахт.

Теоретические основы горной теплофизики были созданы авторами работ /1-4/, которые в последствии были развиты в работах /5-9/. Заметим предварительно, что все методы базируются на решениях уравнений теплового баланса. Авторы работ /5, 7/ справедливо отмечают о несостоятельности существования расчетных зависимостей для вертикальных, наклонных, горизонтальных, очистных выработок, а также их дифференциации в зависимости от времени проветривания.

Здесь же необходимо заметить, что наличие и значимость тех или иных факторов, влияющих на процесс тепломассообмена мезду горным массивом и рудничным воздухом не должны служить поводом для создания множества расчетных методик, ибо физическая модель процесса является общей для любых горных выработок. Поэтому, горные выработки, с точки зрения методов определения тепловлажностных параметров вентиляционной струи, следует различать только по условиям проветривания. Следовательно, принципиально должны лишь различаться методы расчета для тупиковых выработок и для выработок, проветриваемых сквозной струей.

Влияние массообмена на тепловые процессы в шахтах всегда считалось существенным, однако разными авторами оно учитывалось по разному и не всегда корректно, чаще всего эмпирически. Исключение составляют лишь работы /6,7,8/. В работах /6,7/ решено дифференциальное уравнение теплового баланса, где влагосодержание рудничного воздуха принято в виде полного дифференциала от координаты и температуры. Однако, в расчетных формулах фигурируют экспериментальные значения относительной влажности по длине выработки, что фактически сужает область применения предложенных методов и лишает им признак общности.

В работе /8/ впервые решены дифференциальные уравнения теплового и материального балансов, в результате получены расчетные формулы для определения температуры и потенциала массопереноса рудничного воздуха. Однако, формулы эти 
являются весьма громоздкими и справедливы лишь при соблюдении условия $\alpha=\alpha \mathrm{m}$, поэтому их практическое применение ограничено и связано с определенными неудобствами.

Для элементарной длины $\mathrm{d} \ell$ (рисунок) горной выработки, проветриваемой сквозной струей, энергетический и массойвый балансы имеют вид

$$
\begin{gathered}
G c_{p} d t+G_{\tau} d x=k_{\tau} u\left(t_{0} \pm \sigma l \sin \psi-t\right) d l- \\
-K_{T} u_{T}\left(t_{T}-t\right) d l \pm \frac{G l \sin \psi}{427} d l+ \\
+\frac{\sum Q_{M}}{h} d l+q_{0} u^{2} d l, \\
G c_{m} d \theta=K_{\tau m} u\left(\theta-\theta_{0}\right) d l+\frac{\sum W_{M}}{L} d l,
\end{gathered}
$$

где G - масса рудничного воздуха, проходящего по выработке в единицу времени; Cp, $\mathrm{C}_{\mathrm{m}}$ - изобарная теплоемкость и изотермическая массоемкость воздуха; $\mathrm{dt}, \mathrm{d} \theta$ - приращения температуры и потенциала массопереноса воздуха в результате тепломассообмена; - удельная теплота фазового перехода вода-пар; dx - приращение влагосодержания воздуха;

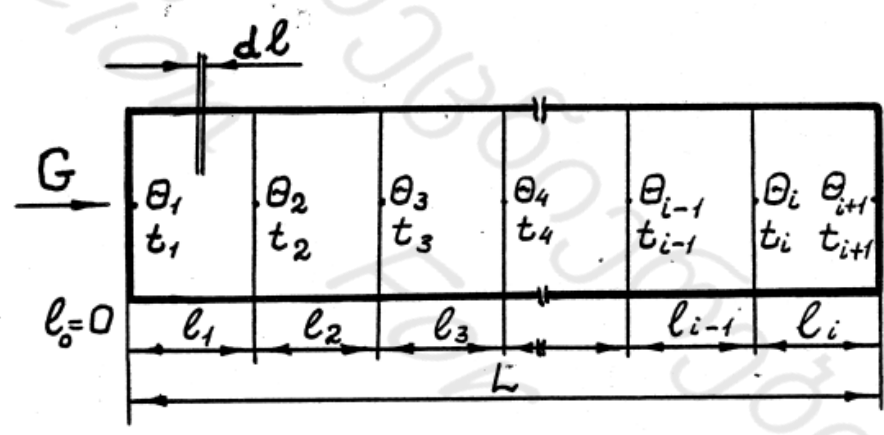
Принципиальная схема к расчету климатических параметров
воздуха в цепи горньх вьработок

$\mathrm{K}_{\tau}, \mathrm{K}_{\tau \mathrm{m}}$ - коэффициенты нестационарного тепло- и массо- обмена; $\mathrm{U}$ - периметр горной выработки; to, $\theta$ (응 - естественная температура и естественный потенциал массопереноса горного массива; $\sigma$ - геотермический градиент; $\Psi$ - угол наклона выработки; $t, \theta$ -

температура и потенциал массопереноса воздушной струи; К $\tau$ - коэффициент теплопередачи трубопровода, расположенного в выработке; UT - периметр трубопровода; $\mathrm{t}$ - средняя температура потока жидкости в трубопроводе; $\Sigma Q_{\mathbf{M}}, \boldsymbol{\Sigma} \mathbf{W}_{\mathbf{M}}$ - сумма тепловыделений и массовыделений от местных источников, к которым в данном случае отнесена и массоотдача от свободной поверхности шахтной воды; L - длина цепи горных выработок; qо - удельное тепловыделение от окислительных процессов.

Условия однозначности

$$
\tau>0, \ell=\ell_{i-1}, \mathrm{t}=\mathrm{t}_{i}, \theta=\theta_{i},
$$


где $\tau$ - время протекания процесса;

$$
i=1,2,3, \ldots, n \text {. }
$$

После несложных преобразований уравнения (I) и (2) соответственно принимают вид

$$
\begin{aligned}
& \frac{d t+\frac{2}{C_{p}} d x}{M-\Pi t \pm K}=d l, \\
& \frac{d \theta}{A\left(\theta_{0}-\theta\right)+B}=d l,
\end{aligned}
$$

где

$$
\begin{aligned}
& M=\frac{1}{G c_{P}}\left(k_{\tau} u t_{0}+k_{T} u_{T} t_{T}+\frac{\sum Q_{M}}{h}\right)+q_{0} u_{;} \\
& \Pi=\frac{1}{G c_{P}}\left(k_{\tau} u+k_{T} u_{T}\right) \\
& K=\frac{l \sin \varphi}{c_{P}}\left(\frac{k_{\tau} u_{\sigma}}{G}+\frac{1}{427}\right) ;
\end{aligned}
$$

$$
\begin{aligned}
& A=\frac{K_{\tau m} U}{G c_{m}} ; \\
& B=\frac{\sum W_{m}}{h G c_{m}} .
\end{aligned}
$$

Апроксимированяая зависимость влагосодержания от относительной влажности, температуры и давления для шахтных условий имеет вид /10/

$$
x=\frac{0,623 \varphi_{n}(t-\varepsilon)}{\bar{D}-P_{c p}},
$$

где $\varphi$ - - относительная влажность воздуха;

n, $\varepsilon$ - коэффициенты апроксимаций;

Б - барометрическое давление;

Рср- среднее парциальное давление водяного пара. 
Значения величин n, $\varepsilon$, Рср в зависимости от пределов апроксимации приведены в табл. 1.

Из определения химического потенциала массопереноса следует, что $\varphi=\exp \theta / \mathrm{RT}$, где $\mathrm{R}$ - универсальная газовая постоянная; $\mathrm{T}$ - абсолютная температура. С учетом этого, уравнение (6) принимает вид

$$
x=D_{1}(t-\varepsilon) \exp \frac{\theta}{\mathrm{RT}} \text {, }
$$

где

$$
\sigma_{1}=\frac{0,623 n}{\sigma-P_{c p}}
$$

Подстановка полного дифференциала от х из формулы (7) в уравнение (4) с учетом (5), приводит к выражению

$$
\begin{aligned}
& \left\{1+\delta_{1} \exp \left[\frac{\theta_{0}+\frac{B}{A}-C \exp (-A l)}{R T}\right] \times\right. \\
& \left.\times\left[1+\frac{\theta_{0}+\frac{B}{A}-C \exp (-A l)}{R T^{2}}\right]\right\}= \\
& =\left\{\frac{\sigma_{1} \varepsilon A C}{R T} \exp \left[\frac{\theta_{0}+\frac{B}{A}-C \exp (-A l)}{R T}\right] \times\right. \\
& \quad x \exp (-A l)+(M-\Pi t \pm K)\} d l,
\end{aligned}
$$

которое не имеет решение, обеспечивающее приемлемую точность.

Поэтому в настоящей работе избран иной путь. Поскольку численное значение Т (К) в данном случае примерно на порядок выше по сравнению с $\mathrm{t}\left({ }^{\circ} \mathrm{C}\right)$, допускается, что приращение температуры на расчетном участке не оказывает существенного влияния на значение $\theta$, а $\varepsilon$ для взятого интервала изменения температуры является величиной постоянной. Поэтому после подстановки $\mathrm{dx}$ из формулы (7) уравнение (4) принимает вид

$$
\frac{1 \pm \frac{\eta}{C_{p}} \delta_{1} \exp \frac{\theta}{R T}}{M-\Pi t \pm K} d t=d l \text {. }
$$


Таблица I

\begin{tabular}{|c|c|c|c|}
\hline $\begin{array}{c}\text { Интервал изменения } \\
\text { температурн }\end{array}$ & $n$ & $\varepsilon$ & $P_{c p}$, Па \\
\hline $0-I 5$ & $7 I, 3$ & $-7,48$ & $I 065,8$ \\
$5-20$ & 95,7 & $-3,06$ & $I 486,8$ \\
$I 0-25$ & $I 26,6$ & $I, 33$ & 2052,6 \\
$I 5-30$ & $I 65,8$ & 5,72 & 2777,3 \\
$20-35$ & $2 I 4,7$ & $I 0,09$ & 3736,8 \\
$25-40$ & 275,3 & $I 4,45$ & 4973,7 \\
$30-45$ & 349,3 & $I 8,79$ & 6539,5 \\
$35-50$ & 438,2 & 23,06 & $85 I 3, I$ \\
\hline
\end{tabular}

Общие интегралы выражений (5) и (8) соответственно имеют

$$
\begin{aligned}
& \theta=\theta_{0}+\frac{B}{A}-C e^{-A R}, \\
& \frac{1+\frac{\partial}{C_{p}} \sigma_{1} \exp \frac{\theta}{R T}}{n} \ln |M-\Pi t \pm K|=l+C .
\end{aligned}
$$

С учетом условий однозначности и после введения обозначения

$$
H_{i, i+1}=\frac{\Pi}{1+\delta_{1} \frac{y}{c_{p}} \operatorname{evep} \frac{\theta_{i+1, i}}{R T_{i, i+1}}}
$$

получаются зависимости для определения потенциала массопереноса и температуры рудничного воздуха при прямом тепловом расчете

$$
\begin{aligned}
& \theta_{i+1}=\theta_{0}+\frac{B}{A}-\left(\theta_{0}+\frac{B}{A}-\theta_{i}\right) e^{-A\left(l_{i}-l_{i-1}\right)}, \\
& t_{i+1}=\frac{M \pm K}{\Pi}-\left(\frac{M \pm K}{\Pi}-t_{i}\right) e^{-H_{i}\left(l_{i}-l_{i-1}\right)} .
\end{aligned}
$$

Для обратного расчета эти формулы соответственно имеют вид

$$
\begin{aligned}
& \theta_{i}=\theta_{0}+\frac{B}{A}-\left(\theta_{0}+\frac{B}{A}-\theta_{i+1}\right) e^{-A\left(l_{i-1}-l_{i}\right)}, \\
& t_{i}=\frac{M \pm K}{\Pi}-\left(\frac{M \pm K}{\Pi}-t_{i+1}\right) e^{-\gamma_{i+1}\left(l_{i-1}-l_{i}\right)}
\end{aligned}
$$


В формулах (13) и (14) знак "+" перед К относится случаю нисходящего движения, а знак “-“ случаю восходящего движения воздуха.

Относительная влажность рудничного воздуха в і́-той очке вычисляется по формуле

$$
\varphi_{i}=e^{\frac{\theta_{i}}{R T_{i}}}
$$

Удобство практического применения предложенного метода рассмотрим на примере прямого расчета. Дело в том, что потенциал массопереноса воздуха является функцией двух переменных - температуры и относительной влажности? при вычислении потенциала по формуле (12) мы знаем лишь суммарное влияние этих двух переменных'в виде $\theta_{i+1}$. В отличие от других методов здесь для вычисления температуры по формуле (13) не требуется наличие значения относительной влажности в точке (ít+1), достаточно значение потенциала массопереноса в этой точке (т.е. знание суммарного эффекта $\varphi$ и t ) с помощью которого по формуле (II) вычисляется

$$
H_{i}=\frac{\Pi}{1+\frac{Z}{C_{p}} \sigma_{f} \exp \frac{\theta_{i+1}}{R T_{i}}}
$$

затем, зная $\theta_{i+1}$ и $\tau_{i+1}$ по формуле (16) можно вычислить значение относительной влажности в этой точке.

Таким образом, предложенный метод выгодно отличается от существующих и является общим для всех месторождений, поскольку в нем отсутствует необходимость применения предварительно определенных экспериментальных или иных значений относительной влажности воздуха.

Рассчтанные нами погрешности определений $\Delta \varphi$, обусловленные принятыми выше допущениями, для Ткибули-Шаорского и Ткварчельского каменноугольных месторождений, принимают значения, приведенные в табл. 2.

Из табл. 2 следует, что даже в том случае, когда приращение температуры рудничного воздуха на расчетном участке достигает 5 градусов, погрешность определения приращений относительной влажности не превышает $10 \%$. Следовательно, получерные с помощью предложенного метода конечные результаты будут достоверными для реальных шахтных условий. 


\begin{tabular}{|c|c|c|}
\hline & & Таблица 2 \\
\hline $\begin{array}{l}\text { Прирапение температурн } \\
\text { воздуха на растетном } \\
\text { у пастке } \Delta t,{ }^{\circ} \mathrm{C}\end{array}$ & $\begin{array}{l}\text { Интервад измене- } \\
\text { ния температуры, } \\
{ }^{\circ} \mathrm{C}\end{array}$ & $\begin{array}{l}\text { Погрешность } \\
\text { определения } \\
\Delta \varphi, \% \%\end{array}$ \\
\hline $\begin{array}{r}I \\
2 \\
3 \\
-4 \\
5\end{array}$ & $\begin{array}{l}I O-40 \\
I O-40 \\
I O-40 \\
I O-40 \\
I O-40\end{array}$ & $\begin{array}{c}2,9 \\
4,8 \\
6,8 \\
8,5 \\
10\end{array}$ \\
\hline
\end{tabular}

\section{ЛИТЕРАТУРА}

1. Щербань А.Н. Основы теории и методы тепловых расчетов рудничного воздуха. М., Углетехиздат, 1953, стр.308.

2. Щербань А.Н., Кремнев О.А. Научные основы расчета и регулирования теплового режима глубоких шахт.; Том 1, Издательство АН УССР, Киев, 1959, стр. 430.

3. Щербань А. Н., Кремнев 0.А. Научные основы расчета и регулирования теплового режима глубоких шахт. Том 2, Издательство АН УССР, Киев, I960, стр.348.

4. Воропаев А.Ф. Управление тепловым режимом в глубоких шахтах. М., Госгортехиздат, 1961, стр.248.

5. Дядькин Ю. Д. Основы горной теплофизики для шахт и рудников Севера. М., Издательство Недра, 1968, стр.256.

6. Единая методика прогнозирования тепловых условий в угольных шахтах. ДонбассМакеевка, Издательство МакНИИ, 1979, стр.196.

7. Кузин В.А., Хохотва Н.Н., Николаенко Л.В. Метод расчета тепловых условий в горных выработках глубоких шахт. В кн.: Охлаждение воздуха в угольных шахтах. МакеевкаДонбасс, Издательство МакНИИ, 1977.

8. Кремнев О.А., Дуравленко В.Я. Тепло- и массообмен в горном массиве и подземных сооружениях, Киев, Издательство Наукова думка, 1980, стр.384.

9. Медведев Б.И. Упрощенный метод теплового расчета цепи горных выработок. В кн.: Тепловые и механические процессы при разработке полезных ископаемых. М., 1965.

10. Свойства влажного воздуха при давлениях 500-100 мм.рт.ст., (авторы Щербань А.Н., Кремнев О.А., Титова Н.М.), М., Госгортехиздат, I960. 